\title{
Novas performances públicas. Os clubes Athleticos e a educação do corpo (Rio de Janeiro, 1884-1889)
}

New public performances. Athletic clubs and the body education (Rio de Janeiro, 1884-1889)

Nuevas performances públicas. Los clubes Atléticos y la educación del cuerpo

(Rio de Janeiro, 1884-1889)

\author{
Victor Andrade de Melo \\ Universidade Federal do Rio de Janeiro (Brasil) \\ http://lattes.cnpq.br/9730234823420258 \\ https://orcid.org/0000-0002-1983-1475 \\ victor.a.melo@uol.com.br
}

\section{Resumo}

No Rio de Janeiro, fundado na década de 1870, o British and American Club foi a primeira sociedade dedicada aos "esportes atléticos", primórdios do atletismo. Dirigido por britânicos, a princípio somente anglófonos participavam das provas de corridas, saltos, arremessos e jogos diversos. No início dos anos 1880, brasileiros começaram a também competir, bem como organizar agremiações próprias. A partir de 1884, houve uma expansão dessas iniciativas. Este estudo teve por objetivo discutir as experiências dos clubs athleticos criados na Corte entre 1884 e 1889. O intuito foi perceber como suas atividades se constituíram em um processo não formal de educação. Como fontes, foram utilizados periódicos publicados na capital nacional. Ao final, se concluiu que a modalidade apresentou novos usos do corpo na cena pública, algo que envolveu os competidores a exibirem uma nova compleição muscular, mas também a assistência que deveria aprender a se vestir e se comportar nas tribunas.

Palavras-chave: História da Educação. Educação do corpo. História do Esporte. 


\begin{abstract}
Founded in the 1870s in Rio de Janeiro, the British and American Club was the city's first association dedicated to "athletic sports", the beginning of athletics. The club was managed by Britons and at first only English speakers could take part on running, jumping and throwing competitions, among other games. In the early 1880 s, Brazilians started competing and also organizing their own associations. The year of 1884 saw the beginning of an expansion in such activities. This study aims at discussing the experiences in athletics clubs created in the Brazilian Empire, between 1884 and 1889. Its goal was to point out how their activities worked as a non-formal process of education. The main sources used in this study were journals published in the Brazilian capital. In the end, it is concluded that sports presented new uses for the body in the public sphere, and this process included both competitors, who displayed a new muscular complexion, and the audience, who needed to learn how to dress and behave in the stands.
\end{abstract}

Keywords: History of Education. Education of the body. History of Sport.

\title{
Resumen
}

En Río de Janeiro, organizado en la década de 1870, el British and American Club fue la primera sociedad dedicada a los "deportes atléticos, principios del atletismo. Dirigido por británicos, al principio solo los angloparlantes participaban en las pruebas de carreras a pié, saltos, lanzamientos y juegos diversos. En el inicio de los años 1880, los brasileños también empezaron a competir, además de fundar sus propias asociaciones. A partir de 1884, hubo una expansión de estas iniciativas. Este estudio tuvo como objetivo discutir las experiencias de los clubes deportivos creados en la Corte entre 1884 y 1889. La intención era entender cómo sus actividades se constituyeron en un proceso educativo no formal. Como fuentes, se utilizaron periódicos publicados en la capital nacional. Al final, se concluyó que eso deporte presentaba nuevos usos del cuerpo en la escena pública, algo que involucraba a los competidores que exhibían públicamente una nueva complexión muscular, pero también el público que debería aprender a vestirse y comportarse en las tribunas.

Palabras clave: História de la Educación. Educación del cuerpo. História del Deporte. 


\section{Introdução}

A estruturação de um mercado de entretenimentos, em geral, se relaciona a algumas importantes mudanças na dinâmica das cidades: uma maior disposição para a ocupação da cena pública (decorrente de certa efervescência política, mas também da circulação de novas ideias sobre a vida em sociedade), bem como uma vitalidade econômica que tem como uma das marcas a conformação de estratos médios que ampliam a base de consumo (CORBIN, 2001; MELO, 2010).

Não há como desprender esses arranjos da diversão de expectativas de comercialização e difusão de novos desejos, algo que tem relação com mudanças observáveis no mundo da produção. Para Porter (2001, p. 57), desde o século XVIII, "a história do uso do tempo livre reproduz, (...), o esquema geral do desenvolvimento da sociedade industrial, sem deixar de refletir alguns de seus paradoxos ${ }^{1}$ ".

Observa-se a articulação de duas noções, consumo e espetáculo, este um conceito que, a despeito de seus limites, expressa não somente o novo formato dos divertimentos, mas sim uma nova dinâmica social, uma maneira de estabelecer mediações com a realidade que envolve todas esferas humanas (CLARK, 2004, p. 43). Nesse cenário, marcado por uma intensa circulação de ideias, produtos e pessoas, se percebem impactos significativos nas experiências corporais:

Em todos esses novos sistemas de circulação, delineia-se o drama da modernidade: um colapso das experiências anteriores de espaço e tempo por meio da velocidade; uma extensão do poder e da produtividade do corpo humano e a consequente transformação deste por meio de novos limiares de demanda e perigo, criando novas formas de disciplina e regulação corporais com base em uma nova observação (e conhecimento) do corpo (GUNNING, 2001, p. 40).

As diversões são, assim, uma importante ocorrência história, expressões de um dado contexto, inclusive no que tange às tensões sociais de um tempo/espaço. Ao seu redor, se percebem as imposições, resistências e negociações de modos de se portar em público, relacionadas às possibilidades de exposição corporal e de usos do corpo.

Esse processo bem se observa no Rio de Janeiro dos anos 1880. Ao mesmo tempo em que se tornaram mais diversos e melhor estruturados os empreendimentos ligados ao entretenimento, percebe-se o crescimento das preocupações no que tange a sua adequação. $O$ processo de distensão social desencadeou tensões diversas relacionadas ao usufruto das diversões.

O que ocorria no Brasil, especificamente na sua capital, guardava similaridades com o quadro europeu ${ }^{2}$. Havia (e há) uma ambiguidade que cercava a maior ocupação da cena pública. Essa excitabilidade não podia se manifestar livremente, tendo que ser restrita por ditames de origens diversas, inclusive da ciência, algo que se exponenciou pelo fato de o corpo ter passado a ser um dos principais objetos de intervenção e investigação (FAURE, 2008).

\footnotetext{
${ }^{1}$ Ao falar de paradoxos, Porter se refere ao fato de que a sociedade industrial estabelece uma intensa dinâmica de trabalho em consonância com um cada vez mais intenso mercado de entretenimento. Emite-se, assim, uma mensagem dúbia: deve-se trabalhar muito, mas também muito se divertir. Essa situação gera um ativismo que acaba por desqualificar os "tempos de não fazer nada". Trata-se, portanto, de uma construção simbólica e material que se articula no reforço dos interesses da sociedade industrial. Por isso, prefiro tratar mais como ambiguidade do que como efetivamente um paradoxo.

${ }^{2}$ Não se trata de pensar numa relação tradicional centro-periferia, na qual no Brasil teríamos copiado exatamente o que houve no continente europeu. De toda forma, estamos alinhados com os autores que percebem que há assimetrias e fluxos de trânsito cultural, percebendo, contudo, as releituras e ressignificações dos processos. Para um debate sobre o tema, ver Maia (2019). Ver também Canclini (1997).
} 
Há que se ter em conta que, no Brasil, aquela década foi marcada por uma intensa dinâmica política, especialmente em função das iniciativas de dois grupos que melhor se estruturaram: abolicionistas e republicanos (CARVALHO, 2012). Além disso, percebe-se a melhor conformação de grupos socioeconômicos distintos, inclusive estratos médios bastante heterogêneos (POPINIGIS, 2007). No âmbito cultural, ampliaram-se os contatos com o "mundo civilizado" europeu (SCHWARCZ, 1998). Acirrou-se o processo de adesão ao ideário e imaginário da modernidade.

Àquela altura, alguns entretenimentos já ofereciam ao público atividades marcadas por maior exposição corporal. Na primeira metade do século XIX, sociedades de dança e arenas de touradas trouxeram para o centro da cena um corpo bastante vestido (MELO, 2015a; MELO, 2016). Em meados da centúria, o esporte começou a se estruturar com o turfe (no qual se utilizavam vestimentas ainda rigorosas) e com o remo (no qual público e principalmente atletas faziam uso de trajes mais leves) (MELO, 2014; MELO, 2015b). Os banhos de mar forjaram uma nova sociabilidade nas praias, uma experiência mais distendida ainda que, a princípio, muito regulada por ditames morais e médicos (MELO, 2015c).

De fato, no caso fluminense, simultaneamente estimulava e restringia essa dinâmica a emergência de um novo conjunto de preocupações com a saúde e higiene. Uma das repercussões desse processo foi a maior oferta nas escolas de conteúdos ligados à educação do corpo, especialmente a dança e a ginástica, expectativa contemplada até mesmo na legislação (PERES, MELO, 2014).

Um indício dessa nova conformação de costumes, como já argumentou Melo (2010), foi a circulação de novos termos. Entre esses, podemos situar "athleta", que passou por uma transição no decorrer do século XIX. Se a princípio era usado para definir tanto aqueles que se envolviam fisicamente em combates quanto os que se dedicam a grandes causas, a partir de meados da centúria, passou a ser progressivamente utilizado para designar os que se dedicavam aos exercícios físicos.

Inicialmente, não havia conotações médicas ou pedagógicas ao seu redor. Definia, por exemplo, os artistas que exibiam proezas acrobáticas ou de força nas arenas circenses. Nos anos 1880, contudo, o termo já era mais usualmente mobilizado para designar os que se dedicavam a práticas corporais com fins "superiores", adequadas aos ideais de civilização e progresso. No que tange aos praticantes de esportes, todavia, ainda se utilizava mais a denominação "sportman", palavra que também se aplicava aos dirigentes de clubes e público costumeiro.

Esse é um dos indicadores que nos leva a considerar interessantes as iniciativas dos clubes que se dedicavam a promover competições de "esportes atléticos", isso é, corridas a pé (na época assim chamadas para as diferenciar das "corridas de cavalos" e "corridas de barcos"), bem como arremessos e saltos (designados "jogos atléticos", termo que também englobava atividades em que habilidades eram testadas, tais como cabo de guerra, corrida do ovo na colher ou corrida de saco).

Num momento em que o esporte era ainda encarado mais como um espetáculo do que como um estilo de vida ligado à saúde e higiene, algo que se tornaria mais usual na década final do século XIX, esses primórdios do atletismo se constituíram em uma importante experiência de transição.

$\mathrm{Na}$ Corte, o pioneiro club athletico foi criado por britânicos na década de 1870: o British and American Club. Nas provas, a princípio, somente podiam tomar parte anglófonos. No início dos anos 1880, brasileiros começaram a participar de competições promovidas por essa sociedade, bem como a fundar agremiações próprias (MELO, 2019a). A partir de 1884, houve uma expansão dessas iniciativas.

Tendo em conta esse debate inicial, este estudo teve por objetivo discutir as experiências dos clubes atléticos criados no Rio de Janeiro entre os anos de 1884 e 1889, momento em que a modalidade se tornou mais reconhecida na cidade, articulada com o fortalecimento do mercado de entretenimentos.

$\mathrm{O}$ intuito foi perceber como tais experiências funcionaram como mecanismos de educação do corpo, considerada, neste estudo, não somente como intervenções mais direcionadas que ocorrem nas instituições formais, mas também como iniciativas cotidianas 
relacionadas à adequação aos costumes, comportamentos e formas de se portar. Temos em conta que é esforço relevante de investigação discutir "as técnicas, pedagogias e instrumentos desenvolvidos para submetê-los (os corpos) a normas" (SOARES, 2001, p. 111).

Para alcance do objetivo, como fontes foram utilizados periódicos publicados no Rio de Janeiro $^{3}$. Consideramos que a imprensa, relevante fórum de debates já no século XIX, importante agência no delineamento das iniciativas de entretenimento, veiculou pontos de vista sobre as distintas modalidades esportivas que merecem atenção por expressar considerações sobre a adequação ou não dessas práticas corporais.

As revistas e jornais foram tratados a partir do que sugere Luca (2005). O perfil dos periódicos será apresentado quando tratar-se de posicionamentos de cronistas, considerados não como expressões da verdade absoluta, mas sim pontos de vista a serem entendidos no espírito do seu tempo. O mesmo não ocorrerá quando as citações fizerem referências a informações factuais, a não ser que se considere que tinham relações com as características do título consultado.

\section{O crescimento do interesse pela modalidade (1884-1885)}

A partir de 1884, o processo de vulgarização dos "esportes atléticos" se ampliou com a criação de novas agremiações que fizeram companhia às pioneiras sociedades que seguiram promovendo seus eventos ${ }^{4}$. O British Amateur Athletic Sports continuou ativo por mais algum tempo, destacando-se, em suas festividades, pela presença cada vez maior de brasileiros no público e entre os competidores. O mesmo ocorria com o Rio Cricket Club, fundado também por britânicos, em 1880, dedicado ao críquete, mas também organizador de provas de athletic sports, ocasiões que gozavam de boa repercussão pública (MELO, 2017a).

Nessas agremiações, quando se ampliou o público dos eventos, a oferta da possibilidade de apostar passou a preocupar alguns membros da colônia britânica. Associados chegaram a se afastar por considerar que os excessos feriam o verdadeiro caráter educacional dos esportes (THE RIO NEWS, 1889a, p. 3) ${ }^{5}$. No Rio Cricket, houve mesmo uma reunião extraordinária de diretoria apenas para decidir a manutenção ou não da venda de poules (JORNAL DO COMÉRCIO, 1884, p. 2).

A preocupação era manter certos parâmetros britânicos no momento em que o maior contato com os fluminenses interferia na dinâmica das competições ${ }^{6}$. O esporte se equilibrava entre duas dimensões: entretenimento e educação. Ambas eram necessárias para o sucesso das iniciativas, mas para alguns os limites deveriam ser claros, com maior valorização do segundo aspecto.

As atividades de dois outros clubes pioneiros, ambos de Niterói, são exemplos da busca de equilíbrio entre essas duas dimensões: o Clube Atlético Brasileiro, criado em 1881, e o Clube Olímpico Guanabarense, fundado em 1883 (MELO, 2019b). Há que se ter em conta que corredores niteroienses costumeiramente participavam de provas no Rio de Janeiro, bem como muitos da capital nacional atravessavam a Baía de Guanabara para demonstrar suas habilidades. Isso se acentuou quando foram criadas mais agremiações.

A princípio, na capital do Império, surgiram alguns clubes de breve duração que contaram exclusivamente com corredores brasileiros, iniciativas que merecem registro por ser uma

\footnotetext{
${ }^{3}$ Os periódicos foram consultados na Hemeroteca Digital da Biblioteca Nacional. Sobre as vantagens, limites e cuidados a serem adotados ao utilizar esse recurso, ver Brasil e Nascimento (2020).

${ }^{4}$ Para mais informações sobre as pioneiras sociedades atléticas, ver Melo (2019a).

5 Esse periódico publicava posicionamentos e informações consideradas relevantes para os anglófonos, inclusive notícias do cotidiano, entre as quais as dos eventos esportivos.

${ }^{6}$ Para um debate sobre a visão britânica de esporte, ver Holt (1989).
} 
demonstração da vitalidade da modalidade. Ao informar a criação do Grêmio Filhos de Tethis, dedicado também à natação, um cronista bem percebeu a movimentação ao redor dos "esportes atléticos": "Alguns jovens, destemidos e ousados, desdenhando, por fáceis, os triunfos alcançados nos clubes atléticos, vão procurar novos triunfos para depois ornarem as frontes, não de louros, mas de coroas de algas entretecidas por lindas nereidas" (O PAIZ, 1885a, p. 2) ${ }^{7}$.

As competições ajudavam a tornar aceitável e para alguns desejável a exibição pública de performances corporais, apresentando novos usos do corpo numa cidade em intensa mudança. Não se tratava de correr com cavalos (turfe) ou com embarcações (remo), mas sim utilizar mais diretamente o próprio corpo como instrumento. As provas eram, em certa medida, menos emocionantes em função da menor velocidade. De outro lado, tratava-se de uma exposição corporal ainda não vista na sociedade fluminense até então.

Algumas agremiações se localizavam nas zonas sul e central da cidade, onde o mercado de entretenimentos já estava melhor estruturado, inclusive no que tange às iniciativas esportivas. Entre outros, podemos citar o Grupo Atlético dos Seis, formado em 1884, promovendo provas no Passeio Público (Centro) (A FOLHA NOVA, 1884a, p. 3). No mesmo ano, foi criada a Sociedade Race Clube com proposta de, no bairro de Botafogo, organizar corridas a pé e de velocípedes (antecedentes do ciclismo, modalidade que usualmente integrou o programa de páreos dos clubes atléticos ajudando a celebrar a valorização da velocidade e outros princípios do progresso $^{8}$ ) (A FOLHA NOVA, 1884b, p. 1).

A prática, todavia, se espraiou também para outras regiões da cidade. Em 1885, abriram as portas o Clube Olímpico Riachuelense (GAZETA DE NOTÍCIAS, 1885, p. 1) e o Clube Atlético Boca do Mato (GAZETA DE NOTÍCIAS, 1884a, p. 2), respectivamente localizados no Riachuelo e no Engenho Novo, bairros da zona norte que cresciam e se tornavam mais habitados. Nas redondezas, no bairro de São Francisco Xavier, em 1886, surgiu o Clube Atlético Recreativo (GAZETA DE NOTÍCIAS, 1886a, p. 2). Em 1887, criou-se o Clube Atlético Leopoldinense (DIÁRIO DE NOTÍCIAS, 1887, p. 4).

Já o Clube Atlético Familiar se instalou num prado próprio localizado na Tijuca (O PAIZ, 1885b, p. 2). Nas cercanias, houve ainda o Clube Atlético Andaraí Grande (GAZETA DE NOTÍCIAS, 1886b, p. 2). Ambos são indicadores da maior ocupação daquela importante região da zona norte. Mais distante, na zona oeste, funcionou o Clube Atlético Realengo (GAZETA DE NOTÍCIAS, 1887, p. 5).

$\mathrm{O}$ aumento do interesse pela modalidade teve também relação com o avanço do processo de urbanização, a conformação de estratos médios e a melhoria dos transportes públicos - o aperfeiçoamento das linhas de bondes e instalação de ferrovias ${ }^{9}$. Conforme a cidade se espraiava, os moradores dos novos bairros progressivamente se interessavam pelos esportes ${ }^{10}$. Para essas novas zonas, longe do mar e por vezes também de hipódromos, os eventos dos clubes atléticos foram as primeiras experiências esportivas, as pioneiras nas quais se visualizou novos usos do corpo e uma mais distendida possibilidade de exposição pública.

\footnotetext{
${ }^{7}$ Jornal de grande circulação, se destacou por seu engajamento nas campanhas abolicionista e republicana. Importantes cronistas do momento escreviam no periódico, boa parte deles desejosos de ver progredir a sociedade fluminense.

${ }^{8}$ Para mais informações sobre o ciclismo, ver Schetino (2009).

${ }^{9}$ Sobre a ocupação dos subúrbios do Rio de Janeiro, ver Fernandes (1995).

${ }^{10}$ Fora da capital, na Província do Rio de Janeiro, também surgiram agremiações. Em 1884, fundou-se, no norte fluminense, o Clube Atlético Campista (GAZETA DE NOTÍCIAS, 1884b, p. 4). Na região sul, em 1885, criou-se o Clube Atlético Vassourense (DIÁRIO DE NOTÍCIAS, 1885a, p. 2) e, em 1886, o Clube Atlético de Barra do Piraí (O PAIZ, 1886, p. 2).
} 
Eminentemente ligadas ao âmbito do entretenimento, não como clubes de associados, surgiram também iniciativas empresariais dedicadas à modalidade. Este foi o caso do Boat Rink, dirigido por Saul Severino, instalado num novo bairro, a Vila Guarani. O estabelecimento era alugado para interessados em promover suas competições ${ }^{11}$ ou acolhia provas organizadas pelo proprietário, que lucrava com as entradas e venda de poules. Chegou a atrair bom público e lograr reconhecimento na cidade, mas logo foi substituído por um hipódromo, o Prado Guarani (CHEVITARESE, MELO, 2018).

Formatos semelhantes tinham outros estabelecimentos que contaram exclusivamente com corredores brasileiros: o Foot Rink (fundado em 1884) e o Club Rink (criado em 1885) (DIÁRIO DE NOTÍCIAS, 1886a, p. 1), ambos localizados no bairro do Estácio, uma região menos nobre da cidade, bem como o Sport Club, instalado no Teatro Politeama, situado na Rua do Lavradio, zona central (DIÁRIO DE NOTÍCIAS, 1886b, p. 4). Neles havia apostas e foram registrados episódios de conflitos em função de polêmicas nos resultados ou desconfiança de armação dos resultados, os conhecidos "tribofes". O Foot Rink chegou a ser destruído pela fúria da turba (DIÁRIO DE NOTÍCIAS, 1885b, p. 2).

Não surpreendentemente esse arranjo empresarial foi contestado por certas lideranças dos clubes britânicos (A FOLHA NOVA, 1885, p. 1) ${ }^{12}$. A questão que se discutia era o que deveria ser considerada adequada utilização dos "esportes atléticos". Se o envolvimento com a modalidade era por alguns desejado, isso deveria seguir determinados ditames, não se confundindo com jogos de azar. Isso é, tratava-se de um debate sobre os bons usos do corpo na cena pública, algo que, com vimos, passava pela maior difusão de discursos médicos e pedagógicos.

De fato, essas iniciativas empresariais não reivindicavam a noção de atletismo (que articulava o físico e o moral com intencionalidades educacionais), mas sim atendiam a uma sociedade que apreciava cada vez mais as diversões públicas e buscava constantemente novidades. Até mesmo por isso, não se deve desprezar sua importância na vulgarização da modalidade.

Elas exponenciavam o perfil híbrido de um esporte que transitava entre o puro agenciamento do espetáculo e os discursos de natureza educativa. Conviviam dois formatos da prática, explicitando tensões que, em maior ou menor grau, sempre percorreram a conformação do campo esportivo e dos entretenimentos em geral. Mais do que uma vinculação a certos discursos, os limites de excitação e de comportamento na esfera urbana foram uma questão que usualmente os cercou.

Esses arranjos ficaram explícitos quando surgiu, em 1885, aquela que se tornaria a mais importante sociedade atlética da ocasião: o Clube Atlético Fluminense.

\section{O Clube Atlético Fluminense (1885-1887)}

Em setembro de 1884, pelos jornais se convidou interessados em participar como acionistas/associados da criação do Clube Atlético Fluminense. No decorrer daqueles meses finais do ano, se podem perceber as ações de estruturação da sociedade, inclusive a confecção dos estatutos, a eleição da primeira diretoria e a construção da sede, localizada na confluência da Rua Conde de Bonfim com a Rua Haddock Lobo, nas redondezas do Largo da Segunda-Feira, Tijuca.

\footnotetext{
${ }^{11}$ Os Fenianos, por exemplo, organizaram alguns eventos no espaço (GAZETA DE NOTÍCIAS, 1884c, p. 3), bem como o Congresso Ginástico Português (O PAIZ, 1885c, p. 2).

${ }^{12}$ Este periódico chegou a gozar de certa notoriedade na época, mas, por problemas financeiros, se uniu ao Brazil, originando o Diário de Notícias.
} 
Tratava-se de uma chácara adquirida de Pompeu Augusto Cesar da Costa, comendador envolvido com o plantio do café, cultivo antes comum no bairro que mudava de perfil, abandonando suas feições rurais. A Tijuca se modernizava e a nova agremiação era indicador desse processo. Há que se ter em conta que, no decorrer da segunda metade do século XIX, progressivamente no bairro foram se instalando fábricas e hotéis, aproveitando a fartura de água. Em decorrência, também se instalou uma estrutura de transporte público.

A sede foi planejada para acolher corridas (uma raia de 300 por 8 metros), mas também a prática de tiro ao alvo, patinação, esgrima, ginástica, entre outros (A FOLHA NOVA, 1884c, p. 1). Esse é um diferencial importante: o caráter multiesportivo da agremiação. $O$ esmero na preparação das instalações foi acompanhado amiúde pela imprensa que, desde os primeiros momentos, encheu de loas a iniciativa. Oferecendo confortos diversos, poderia acolher cerca de 2000 pessoas - ainda que, por vezes, os cronistas tenham sugerido um público bem maior.

Perceba-se que se tinha associados, o Clube Atlético Fluminense também manifestava a intenção de atrair público com a cobrança de ingresso. Para tal, diversas estratégias foram entabuladas. Inaugurada com grande festa, em julho de 1885, ocasião que contou com a presença da família imperial e importantes personagens da cidade, a sede se notabilizou por permanecer aberta diariamente e oferecer uma intensa e variada programação.

Não poucas vezes, a agremiação foi elogiada por esse dinamismo: "O Clube Atlético conseguiu sobressair desde o dia de sua inauguração não só pela sua boa direção como também pelo modo porque procura desempenhar os fins aos quais se propôs, e o resultado aí está no acolhimento que encontrou por parte do público" (DIÁRIO DE NOTÍCIAS, 1885c, p. 1) ${ }^{13}$. Mais do que outras experiências, em função da variedade e regularidade de ofertas, explicitouse a questão dos usos do corpo na cena pública.

Os corredores que treinavam cotidianamente se aproximavam dos hábitos de remadores, personagens que ainda não eram notórios, mas já estavam a caminho de se tornar insignes por seus costumes e porte corporal, algo que iria se manifestar mais claramente na década final do século (MELO, 2001). Onde não havia mar, existiam clubes atléticos. Em ambos, corpos se exibiam em performances crescentemente apreciadas.

Mesmo que o clube se encontrasse mais distante das zonas central e sul, atraiu gente que por lá vivia. Um cronista observou que era grande a quantidade de bondes que chegavam à Tijuca nos dias de eventos (DIÁRIO DE NOTÍCIAS, 1885d, p. 1). Nessas ocasiões, a Companhia de São Cristóvão, a partir de intervenção de Paulo de Frontin, já envolvido com o esporte e na ocasião liderando a instalação do Derby Clube, constantemente ampliou o número de veículos das linhas que atendiam o bairro, bem como ofereceu opções extras diretas partindo do Largo de São Francisco.

Vale o registro de que não só a cidade passava a pulsar numa região que há bem pouco tempo era basicamente rural, como também deslocava-se gente de outras zonas da capital para assistir os eventos promovidos por lá. Na verdade, a agremiação antecipou e integrou a dinâmica de diversão que seria garantida por quatro hipódromos que seriam instalados nas redondezas na metade final dos anos 1880. Desde 1849, já havia o Prado Fluminense, que se tornou mais ativo a partir da década de 1870 (MELO, 2001).

\footnotetext{
${ }^{13}$ Periódico de perfil republicano, bateu-se constantemente pela modernização do país.
} 
Figura 1 - Detalhe da planta da cidade do Rio de Janeiro e subúrbios, com marcação, em lilás, dos cinco hipódromos da cidade e, em vermelho, da região do Clube Atlético Fluminense.

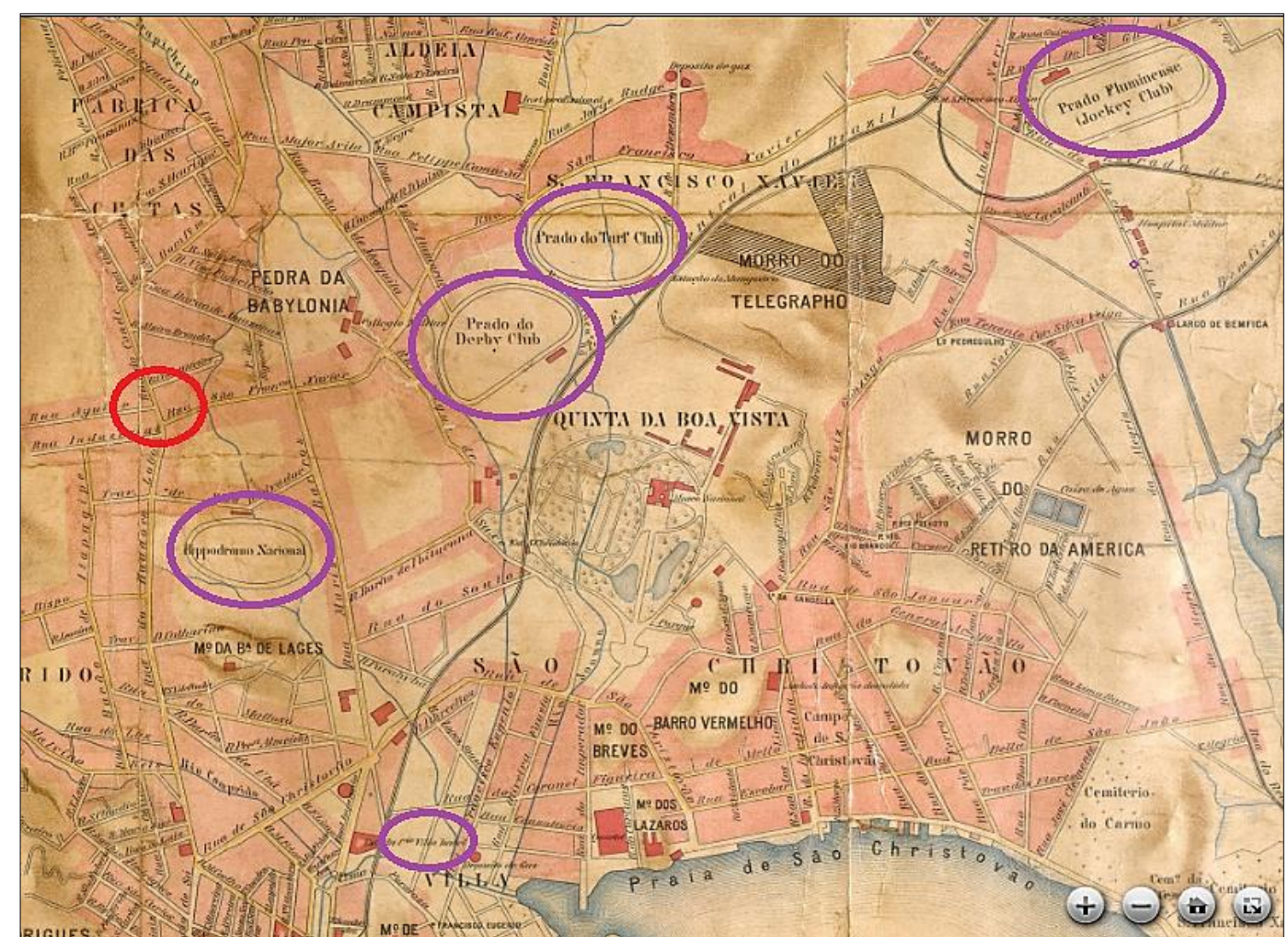

Fonte: Biblioteca Digital Luso-Brasileira. Disponível em https://bdlb.bn.gov.br/acervo/handle/20.500.12156.3/27205. Acesso em 18 ago. 2020.

A repercussão pública do Clube Atlético Fluminense chegou a ser reconhecida por Artur Azevedo - literato, jornalista e dramaturgo sempre atento ao que ocorria na cidade, inclusive usualmente mobilizando o esporte para entabular críticas sociais (KNIJNIK, MELO, 2015). Ele inseriu uma referência à agremiação em uma de suas peças de revista, O Bilontra, de 1885, fazendo uma comparação com o Derby Clube. Os personagens sugeriam uma diferença entre os fins das duas sociedades (também supondo que uma parte da assistência preferia mesmo as corridas de cavalos):

1o. SPORTMAN - Deixem lá! É o mais bonito dos prados!

2o. SPORTMAN - Eu prefiro o Clube Atlético Fluminense, que também se inaugurou este ano.

1o. SPORTMAN - Pelo amor de Deus, Senhor Xavier, não confunda as coisas. Clube é clube, e prado é prado.

2o. SPORTMAN - Isso sei eu; não me dá novidade.

1o SPORTMAN - E lá quanto a corridas, antes quero as de animais. Isto de burrinhos sem cauda não é comigo.

Nesse diálogo percebemos uma vez mais as duas dimensões que cercavam o fenômeno esportivo. Os páreos de turfe eram mais puro entretenimento, ao seu redor havendo pouco discursos de saúde e higiene. Já as provas de corridas a pé, arremessos e saltos podiam até ser menos emocionantes, por ser menos velozes, mas dramatizavam mais intensamente as possibilidades de usos do corpo a partir de certos princípios.

Esse aspecto ficou claro quando o clube promoveu um dos eventos que contribuiu para a popularização da modalidade: com grande festa e cerimônia, recebeu Bargossi e a esposa, 
corredores europeus de fama internacional, para disputar provas e fazer demonstrações de suas habilidades de velocidade e resistência (DIÁRIO DE NOTÍCIAS, 1885c, p. 1) ${ }^{14}$.

Os atletas, que chegaram a ser recebidos pelo imperador, também se apresentaram em outros espaços da cidade. A repercussão dessas exibições foi registrada durante anos nos jornais. Como bem sugeriu um cronista: "Agora que o Bargossi está aqui, todos querem mostrar que se não têm umas gambias como as dele, ao menos procuram a todo o transe obter umas que rivalizem com as de tão famoso andarilho" (DIÁRIO DE NOTÍCIAS, 1885e, p. 1).

O corredor também chamou a atenção de Artur Azevedo, que dedicou algumas crônicas ao "andarilho dos andarilhos" (DIÁRIO DE NOTÍCIAS, 1885f, p. 1). Para ele, sempre com uma pitada de ironia:

É um magnífico tipo da forte raça humana, alegre, vivo, inteligente, sadio. Gesticula como um ator de província e fala pelas tripas de Judas... Tem andado pedibus calcante por toda a Europa, e não será para admirar que um dia faça deveras o mesmo que o Vasques tantas vezes tem feito por troça: a viagem à volta do mundo a pé. (...). Um homem que tanto corre deve ser, realmente, objeto de admiração num país que tão lentamente caminha. As pernas de Bargossi têm músculos de ferro (DIÁRIO DE NOTÍCIAS, 1885f, p. 1).

O "homem-locomotiva", metáfora explícita das representações modernas que o cercavam, mereceu até mesmo uma gravura no Diário de Notícias, retratado com imagem desafiadora, trajado de maneira menos formal, exibindo uma masculinidade altiva ${ }^{15}$.

Figura 2 - Imagem de Bargossi

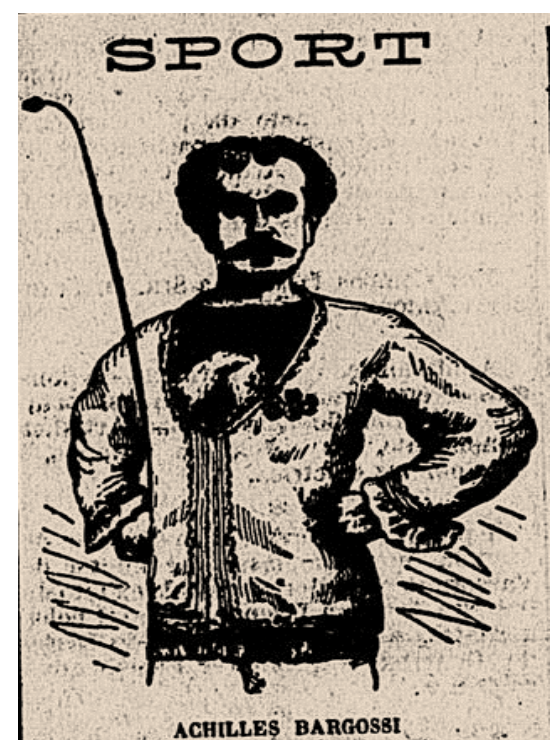

Fonte: Diário de Notícias, 16 ago. 1885, p. 1

\footnotetext{
${ }^{14}$ Achilles Bargossi nasceu em 22 de abril de 1847, na cidade de Forlí, Itália. Era um personagem não raro do século XIX, utilizando determinadas habilidades para ganhar a vida se apresentando nos espaços que crescentemente se abriam com a expansão do mercado de entretenimentos. Tratava-se de um momento de transição entre as exibições circenses e as esportivas no sentido moderno (MELO, PERES, 2014). Exibiu suas capacidades em muitos países do continente europeu e americano (algo possível porque melhoraram sensivelmente os meios de transporte, especialmente, nesse caso, a eficiências dos navios a vapor).

15 O tema mereceu uma reflexão de Fabio Peres no blog História(s) do Sport. Ver: $<$ https://historiadoesporte.wordpress.com/2014/08/24/mercado-de-entretenimento-saude-e-praticas-corporais-no-seculoxix-a-historia-do-artista-atleta-bargossi-e-de-sua-familia-no-rio-de-janeiro-parte-1/>. Acesso em: 11 fev. 2020.
} 
Na mesma ocasião, surgiu um primeiro corredor brasileiro de destaque, Germano de Almeida, desafiante de Bargossi, pioneiro de "heróis" que recebiam muita atenção e elogios da imprensa, exaltados como exemplos para a juventude, estímulos para a adoção do hábito de fazer algum exercício físico (GAZETA DE NOTÍCIAS, 1885b, p. 1) ${ }^{16}$. Se o espetáculo público funcionava como uma educação de sentidos ao apresentar outras possibilidades de usos do corpo, esses "sportmen" era representados como portadores das mensagens de um novo tempo, cujo desafio era chegar no mesmo patamar das sociedades ditas mais civilizadas.

De fato, vale observar que em vários momentos os jornais registraram o grande número de inscritos nas provas. No Clube Atlético, por vezes beiraram os 300 por competição, inclusive muitas mulheres, que ocuparam um espaço constante e importante nos páreos ${ }^{17}$. Mais ainda, com o decorrer do tempo, foi se adotando um formato mais próximo do que hoje temos nas competições de atletismo.

Muitos cronistas começaram a registrar o forjar do novo hábito: "E então? Desenvolve-se ou não o gosto pelas corridas?" (DIÁRIO DE NOTÍCIAS, 1885f, p. 1). Mesmo considerando que tal posição poderia se marcada por otimismos de quem apoiava o desenvolvimento esportivo, não há como desprezar as contribuições dos clubes atléticos para a vulgarização da prática.

O perfil dos dirigentes do Clube Atlético Fluminense era uma expressão do grupo envolvido. Dois presidentes assumiram a primeira gestão. Antonio Pereira de Araujo Bessa era maçom e empresário ligado a um pequeno empreendimento, a Companhia Industrial de Encaixotamentos, enquanto José Coelho Barbosa era proprietário de uma farmácia homeopática, membro do Instituto Hahnemanniano. Como secretários, atuaram importantes comerciantes, João de Azevedo Fernandes Guimarães e Jacintho Pinto de Lima Junior (futuro presidente do Clube de Regatas do Flamengo).

Como os diretores, os sócios eram parte de um estrato médio, moradores das redondezas da Tijuca ou da zona central, envolvidos com profissões ligados ao "progresso" da cidade engenheiros, militares, médicos, farmacêuticos, pequenos empreendedores. Não surpreende, assim, que a modalidade tenha sido interpretada com fins utilitários: utile Dulce, uma dimensão que sempre marcou o desenvolvimento do campo esportivo (MELO, 2014). Nesses discursos, não dever-se-ia incentivar qualquer diversão, mas sim aquelas que pudessem trazer algum ganho simbólico e material para a sociedade e para a nação.

Um dos exemplos dessa vinculação é o fato de que a diretoria programava com frequência páreos para crianças e jovens sempre anunciando intuitos de contribuir para a educação da juventude por meio de uma experiência civilizada e saudável. Até mesmo por isso, a existência da poule, em certa medida, era relevada pelos críticos, já que os lucros eram investidos na melhoria das instalações e funcionamento da agremiação.

Para um cronista, a fim de evitar ter que recorrer a essa estratégia de manutenção, os clubes atléticos mereceriam receber investimentos governamentais já que supostamente estimulavam hábitos importantes para cidadãos que deveriam estar prontos para proteger a nação (DIÁRIO DE NOTÍCIAS, 1885a, p. 2), uma preocupação que crescera em decorrência da Guerra do Paraguai (SILVA, MELO, 2011). As corridas seriam, inclusive, a seu ver, uma boa ferramenta para treinamento militar. Até mesmo por isso, certos defensores da prática preferiam as provas de resistência às de velocidade (DIÁRIO DE NOTÍCIAS, 1885h, p. 1).

Havia também sugestões de que a modalidade poderia trazer benefícios para a saúde, para o desenvolvimento da "musculatura dos órgãos motores e a capacidade dos pulmões" (DIÁRIO DE NOTÍCIAS, 1885i, p. 1), algo que, na verdade, ainda era efetivamente pouco

\footnotetext{
${ }^{16}$ Foi um dos principais e mais influentes periódicos do Rio de Janeiro do século XIX, no qual atuavam importantes cronistas que lançaram olhares críticos para a sociedade fluminense.

${ }^{17}$ Não é nosso objetivo neste artigo discutir a participação feminina. Deve-se, contudo, registrar que os "esportes atléticos" foram importantes no que tange a um maior protagonismo e presença das mulheres na cena pública.
} 
compreendido. De toda forma, trata-se de mais um indicador da influência do pensamento médico na regulação e incentivo a novos usos do corpo.

O principal aventado, contudo, era a potencial contribuição para o desenvolvimento social a partir de uma experiência civilizada. Como sugeriu o cronista Sportman, especializado no tema: "Tudo que há de elegante no high-life fluminense dera-se ali rendez-vous, marcara alegre encontro" (GAZETA DA TARDE, 1885, p. 2) ${ }^{18}$.

Tratava-se de uma experiência menos formal, mais marcada pelo conforto do que pelo luxo, o que movimentava os frequentadores da elite, especialmente as mulheres, a buscar as vestimentas mais adequadas. Pelos jornais, se ressaltava essa necessidade de trajar-se para os eventos atléticos tendo em conta o novo espírito público. Se novos usos do corpo estavam em cena, havia que se explicar os procederes e limites dessas novas ocasiões.

O progresso, ideia tão veiculada nas ações da agremiação, não admitia as velhas exibições de roupas muito pesadas. Tampouco deveriam ser por demais curtas. Havia uma nova elegância a ser buscada, mais um indício de regulação corporal. Tratava-se de um fórum de negociações tendo em vista o quadro de mudanças no âmbito cultural e econômico - novos hábitos e novos produtos dialogavam na constituição de uma possibilidade renovada de se trajar ${ }^{19}$.

Demonstrando seu espírito progressista, outras ações tomou a diretoria do Clube Atlético. Por exemplo, contribuiu com causas assistenciais, inclusive aquelas ligadas à libertação de escravos, se juntando a outras sociedades do âmbito do entretenimento que se engajaram na causa (MELO, PERES, 2014). Ao mesmo tempo, jamais descuidou do público, inserindo atividades diversas para tornar mais atrativos seus programas, usualmente oferecendo competições ou exibições de modalidades distintas, para além do restaurante e dos belos jardins, nos quais constantemente havia apresentações musicais.

O Clube Atlético Fluminense rapidamente se integrou ao meio esportivo do Rio de Janeiro. Uma equipe de remo disputava provas promovidas pelo Clube de Regatas Guanabarense. Instituíram-se aulas de ginástica e uma parceria com o Clube Ginástico Português. Tornou-se o principal espaço de patinação quando o antigo Skating-Rink fechou as portas (MELO, 2017b). Várias agremiações e escolas usaram suas instalações para organizar eventos atléticos. Tornou-se um "centro de educação physica", um núcleo irradiador do costume da prática de exercícios físicos.

A despeito do sucesso, em 1887, o clube deixou de existir. Não sabemos exatamente por quais motivos, mas é possível inferir algo sobre o fim de sua trajetória. Na primeira metade desse ano, parece ter havido algum desconforto na diretoria que interferiu no funcionamento da agremiação, dificuldades de renovação e de mobilização dos associados (GAZETA DA TARDE, 1887a, p. 2). Em julho, uma comissão provisória tentou recuperar a dinâmica anterior (O PAIZ, 1887a, p. 2). Nesse mês, foi ainda promovido um evento, aparentemente com o usual sucesso (GAZETA DA TARDE, 1887b, p. 2). Em setembro, as instalações foram cedidas para uma atividade da Escola Alemã. Em outubro, ficou claro que os esforços não parecem ter logrado sucesso com a instituição de uma comissão liquidante (O PAIZ, 1887b, p. 2). Logo se anunciava o leilão de seus bens e do terreno da sede (O PAIZ, 1887c, p. 2).

De fato, na transição dos anos 1880 e 1890 , houve problemas diversos que cercaram as agremiações atléticas. Talvez até mesmo o excesso de atividades tenha contribuído para o seu declínio. A sociedade fluminense cada vez mais valorizava as novidades. Além disso, não era fácil viabilizar financeiramente as iniciativas. As apostas eram sempre um elemento importante para tal. Todavia, naquele momento, uma série de debates houve ao redor de sua proibição.

Para além dos incômodos dos britânicos com a perda do caráter educacional, o Ministério do Império, o delegado Costa Ferraz e José do Patrocínio, na condição de vereador,

\footnotetext{
${ }^{18}$ Dirigido por José do Patrocínio, esse periódico se destacava por seu caráter abolicionista e dedicar atenção aos grupos minoritários da cidade.

${ }^{19}$ Para um debate sobre o tema, ver, entre outros, Souza (1987) e Assunção e Italiano (2018)
} 
propuseram posturas para restringir e regularizar as apostas, desencadeando grande debate público $^{20}$. Em geral, isso atingiu mais os clubes de turfe, mas eventos de remo e de atletismo também sentiram impactos, inclusive em função do estabelecimento de impostos e suspensão das poules, o que dificultava seus mecanismos de manutenção. Além disso, a Câmara proibiu a realização de atividades esportivas entre dezembro e abril, supostamente por preocupações com a saúde no tempo de verão (DIÁRIO DE NOTÍCIAS, 18871, p. 1).

Em Niterói, o Olímpico Guanabarense e o Atlético Brasileiro também fecharam suas portas, respectivamente em 1887 e 1888 (MELO, 2019b). Na capital nacional, o Rio Cricket ainda promoveu seus eventos até 1889 (THE RIO NEWS, 1889, p. 2), mas passou por uma grande crise de identidade, acentuada com a proclamação da República, que impactou diretamente seu funcionamento (MELO, 2017a). O British Club, da mesma forma, não resistiu e cerrou suas portas. No Rio de Janeiro, todas as agremiações citadas se extinguiram, mas outras foram criadas.

Em 1889, promoveram corridas o Clube Oito de Setembro e o Clube Olímpico Fluminense, o último no bairro de São Cristóvão. Nesse mesmo ano, em Sampaio se criou o Clube Esportivo Nove de Julho. Em 1890, o Clube Campesino organizou provas no Riachuelo. Numa região mais distante do Centro foram fundados o Clube Atlético de Irajá (com sede em Madureira) e outro Clube Atlético Brasileiro (em Cascadura). A modalidade seguia se estruturando nas zonas mais afastadas da região central.

Merece também registro o Clube Atlético Guanabarense, dedicado às corridas a pé e de velocípede, fundado em 1889, no bairro de Botafogo, aproveitando uma excitabilidade pública já forjada com as regatas desde meados do século XIX, notadamente a partir das iniciativas do Clube de Regatas Guanabarense e do Clube Guanabarense.

A popularidade podia não ser a mesma, mas pode-se dizer que a continuidade da criação de clubes atléticos demonstra que estava instituído um gosto na população fluminense, algo que se exponenciaria e ganharia outros formatos nas décadas seguintes.

\section{À guisa de conclusão}

Os "esportes atléticos", primórdios do atletismo, no decorrer dos anos 1870 e 1880, foram se difundindo no Rio de Janeiro, passando de uma modalidade eminentemente valorizada pelos anglófonos, pioneiros na estruturação de iniciativas, para uma assistida e depois praticada também por brasileiros, que por sua vez deram a ela conotações próprias, algumas vezes se chocando mesmo com o que pensava a colônia britânica.

A vulgarização da modalidade foi tributária de uma dinâmica na qual mais intensamente se desenvolveu um mercado de entretenimentos que se articulava com o processo de adesão ao ideário e imaginário da modernidade, a maior filiação a noções de civilização e progresso.

Além de trânsitos culturais, relacionados à influência de estrangeiros, a criação de sociedades atléticas foi também uma expressão e indicador do aumento da zona urbana da cidade, da necessidade de ampliar o local de moradia para gente de estratos médios que se tornavam melhor delineados em função das mudanças socioeconômicas. Deve-se considerar que facilitava o funcionamento das agremiações dedicadas aos "esportes atléticos" o fato de necessitarem de menor estrutura do que as turfísticas e náuticas.

A modalidade foi um elo entre o momento em que a prática esportiva era eminentemente concebida como espetáculo para outro em que também ao seu redor se desenvolveu mais efetivamente uma base moral ligada a discursos médicos e pedagógicos. Não é raro, portanto, que algumas ações dos clubes atléticos tenham se cruzado com outras iniciativas do campo esportivo ou da ginástica, na mesma medida em que houve experiências que adotaram uma estrutura eminentemente empresarial.

\footnotetext{
${ }^{20}$ Ver, por exemplo, Diário de Notícias (1887j, p. 1) e Diário de Notícias (1887k, p. 2).
} 
Nesse cenário, se percebeu as tensões que cercavam a prática esportiva, algo que tinha em conta os bons usos do corpo e da cidade. O Clube Atlético Fluminense conseguiu articular as duas dimensões em debate, adotando dinâmicas espetaculares, mas também iniciativas e discursos que ressaltavam as preocupações com a educação, saúde e higiene. Com isso, logrou grande aceitação e respeitabilidade social. A despeito de seu pouco tempo de existência, deu grandes contribuições à difusão da modalidade e conformação do esporte em geral no Rio de Janeiro. No que tange a um processo de educação corporal, também, como procuramos argumentar.

Enfim, os esportes atléticos desempenharam bem a função de apresentar novos usos do corpo na cena pública, algo que envolveu os competidores a exibirem uma nova compleição muscular, mas também o público que deveria aprender a se vestir e se comportar nas tribunas. Os limites desses comportamentos se estabeleciam na tensão entre o puro agenciamento do espetáculo e os ditames de ordem médica e pedagógica. Tratou-se, claramente, de um processo de educação do corpo.

Valerá, no futuro, investigar as experiências dos clubes atléticos na virada dos séculos XIX e XX, quando já estavam mais consolidados os discursos que relacionavam o esporte a parâmetros de saúde e higiene, bem como adotou-se um padrão de moralidade que definitivamente condenou as apostas e elegeu os atletas como importantes personagens sociais.

\section{Referências}

A FOLHA Nova, Rio de Janeiro, 20 out. 1884b.

A FOLHA Nova, Rio de Janeiro, 25 mar. 1885.

A FOLHA Nova, Rio de Janeiro, 29 jun. 1884a.

A FOLHA Nova, Rio de Janeiro, 3 dez. 1884c

ASSUNÇÃO, Beatriz Albarez de; ITALIANO, Isabel Cristina. Moda e vestuário nos periódicos femininos brasileiros do século XIX. Revista do Instituto de Estudos Brasileiros, São Paulo, n.71, p.232-251, dez. 2018. https://doi.org/10.11606/issn.2316-901X.v0i71p232-251

BRASIL, Eric; NASCIMENTO, Leonardo Fernandes. História digital: reflexões a partir da Hemeroteca Digital Brasileira e do uso de CAQDAS na reelaboração da pesquisa histórica. Estudos Históricos, Rio de Janeiro, v. 33, n. 69, p. 196-219, jan.-abr. 2020. https://doi.org/10.1590/s2178-14942020000100011

CANCLINI, Néstor García. Culturas híbridas: estratégias para entrar e sair da modernidade. São Paulo: Edusp, 1997.

CARVALHO, José Murilo. A vida política. In: CARVALHO, José Murilo (coord.). História do Brasil Nação (1808-2010) - volume 2 - A construção nacional (1830-1889). Rio de Janeiro: Objetiva, 2012. p. 83-130.

CHEVITARESE, André Leonardo; MELO, Victor Andrade de. Embates na sociedade fluminense: a experiência do Prado Guarany (1884-1890). Revista Brasileira de História, São Paulo, v.38, n.78, p.235-258, 2018. https://doi.org/10.1590/1806-93472018v38n78-11

CLARK, T. J. A pintura da vida moderna. São Paulo: Companhia das Letras, 2004. 
CORBIN, Alain (org.). História dos tempos livres. Lisboa: Teorema, 2001.

DIÁRIO de Notícias, Rio de Janeiro 22 mar. 18871.

DIÁRIO de Notícias, Rio de Janeiro, 1 jul. 1886a.

DIÁRIO de Notícias, Rio de Janeiro, 10 ago. 1885c.

DIÁRIO de Notícias, Rio de Janeiro, 12 ago. 1885a.

DIÁRIO de Notícias, Rio de Janeiro, 14 ago. 1885 e.

DIÁRIO de Notícias, Rio de Janeiro, 16 out. 1885g.

DIÁRIO de Notícias, Rio de Janeiro, 2 fev. 1886b.

DIÁRIO de Notícias, Rio de Janeiro, 20 ago. 1887.

DIÁRIO de Notícias, Rio de Janeiro, 23 ago. 1885h.

DIÁRIO de Notícias, Rio de Janeiro, 24 abr. 1887k.

DIÁRIO de Notícias, Rio de Janeiro, 24 ago. 1885b.

DIÁRIO de Notícias, Rio de Janeiro, 26 fev. 1887j.

DIÁRIO de Notícias, Rio de Janeiro, 27 jul. 1885d.

DIÁRIO de Notícias, Rio de Janeiro, 3 dez. $1885 i$.

DIÁRIO de Notícias, Rio de Janeiro, 31 jul. $1885 f$.

FAURE, Olivier. O olhar dos médicos. In: CORBIN, Alain; COURTINE, Jean-Jacques; VIGARELLO, Georges (orgs.). História do corpo. Da Revolução à Grande Guerra. Volume II. Rio de Janeiro: Vozes, 2008. p. 13-55.

FERNANDES, Nelson da Nobrega. O rapto ideológico da categoria subúrbio. Rio de Janeiro: UFRJ, 1995.

GAZETA da Tarde, Rio de Janeiro, 10 ago. 1885.

GAZETA da Tarde, Rio de Janeiro, 11 jul. 1887b.

GAZETA da Tarde, Rio de Janeiro, 7 set. 1887a.

GAZETA de Notícias, Rio de Janeiro, 10 ago. 1885 b.

GAZETA de Notícias, Rio de Janeiro, 12 jun. 1887.

GAZETA de Notícias, Rio de Janeiro, 12 nov. 1884c. 
GAZETA de Notícias, Rio de Janeiro, 19 out. 1884b.

GAZETA de Notícias, Rio de Janeiro, 21 mai. 1886a.

GAZETA de Notícias, Rio de Janeiro, 21 nov. 1884a.

GAZETA de Notícias, Rio de Janeiro, 28 abr. 1885.

GAZETA de Notícias, Rio de Janeiro, 8 mai. 1886 b.

GUNNING, Tom. O retrato do corpo humano: a fotografia, os detetives e os primórdios do cinema. In: CHARNEY, Leo; SCHWARTZ, Vanessa (orgs.). O cinema e a invenção da vida moderna. São Paulo: Cosac \& Naify Edições, 2001. p. 39-80.

HOLT, Richard. Sport and the British: a modern history. New York: Oxford University Press, 1989.

JORNAL do Comércio, Rio de Janeiro, 4 ago. 1884.

KNIJNIK, Jorge; MELO, Victor Andrade de. Uma nova e moderna sociedade? O esporte no teatro de Arthur Azevedo. Revista Brasileira de Ciências do Esporte, Florianópolis, v. 37, n. 1, p. 11-19, jan.-mar. 2015. https://doi.org/10.1016/j.rbce.2012.05.001

LUCA, Tânia Regina. História dos, nos e por meio dos periódicos. In: PINSKY, Carla B. (org.). Fontes históricas. São Paulo: Ed. Contexto, 2005. p. 111-153.

MAIA, João Marcelo E. Costa Pinto em dois tempos: os efeitos periféricos na circulação de ideias. Tempo Social, São Paulo, v. 31, n. 2, p. 173-198, 2019. https://doi.org/10.11606/01032070.ts.2019.148331

MELO, Victor Andrade de. "Pois temos touros?": as touradas no Rio de Janeiro do século XIX (1840-1852). Análise Social, Lisboa, v. 50, p. 382-404, $2015 a$.

MELO, Victor Andrade de. A sociabilidade britânica no Rio de Janeiro do século XIX: os clubes de cricket. Almanack, Guarulhos, v.16, p.168-205, 2017a. https://doi.org/10.1590/2236$\underline{463320171604}$

MELO, Victor Andrade de. Antes do club: as primeiras experiências esportivas na capital do império (1825-1851). Projeto História, São Paulo, v. 49, p. 1-40, 2014.

MELO, Victor Andrade de. Cidade Sportiva: primórdios do esporte no Rio de Janeiro. Rio de Janeiro: Relume Dumará/Faperj, 2001.

MELO, Victor Andrade de. Enfrentando os desafios do mar: a natação no Rio de Janeiro do Século XIX (anos 1850-1890). Revista de História, São Paulo, n.172, p.299-334, jan.-jun., 2015c. https://doi.org/10.11606/issn.2316-9141.rh.2015.98755

MELO, Victor Andrade de. Esporte e lazer: conceitos - uma introdução histórica. Rio de Janeiro: Apicuri/Faperj, 2010. 
MELO, Victor Andrade de. Experiências de ensino da dança em cenários não escolares no Rio de Janeiro do século XIX (décadas de 1820-1850). Movimento, Porto Alegre, v.22, n.2, p.497-508, 2016. https://doi.org/10.22456/1982-8918.56852

MELO, Victor Andrade de. O espetáculo que educa o corpo: clubes atléticos na cidade de Niterói dos anos 1880. História da Educação, Pelotas, v. 23, e85836, p. 1-34, 2019b. https://doi.org/10.1590/2236-3459/85836

MELO, Victor Andrade de. O sport em transição: Rio de Janeiro, 1851-1866. Movimento, Porto Alegre, v. 21, n. 2, p. 363-376, 2015b. https://doi.org/10.22456/1982-8918.49489

MELO, Victor Andrade de. Trânsitos culturais: as experiências dos primeiros clubes athleticos do Rio de Janeiro (1873-1883). Movimento, Porto Alegre, p. e25098, dez. 2019a. Disponível em: <https://seer.ufrgs.br/Movimento/article/view/90653>. Acesso em: 11 fev. 2020. $\underline{\text { https://doi.org/10.22456/1982-8918.90653 }}$

MELO, Victor Andrade de. Uma diversão civilizada - a patinação no Rio de Janeiro do século XIX (1872-1892). Locus, Juiz de Fora, v.23, n.1, p.81-100, 2017b. https://doi.org/10.34019/2594-8296.2017.v23.20843

MELO, Victor Andrade de; PERES, Fabio de Faria. A gymnastica no tempo do Império. Rio de Janeiro: 7 Letras, 2014.

O PAIZ, Rio de Janeiro, 10 jul. 1887a.

O PAIZ, Rio de Janeiro, 16 out. $1887 \mathrm{~b}$.

O PAIZ, Rio de Janeiro, 18 nov. 1885a.

O PAIZ, Rio de Janeiro, 20 dez. 1886.

O PAIZ, Rio de Janeiro, 24 mai. 1885c.

O PAIZ, Rio de Janeiro, 26 out. 1887c.

O PAIZ, Rio de Janeiro, 27 set. 1885 b.

PERES, Fabio de Faria; MELO, Victor Andrade de. O corpo da nação: posicionamentos governamentais sobre a educação física no Brasil monárquico. História, Ciências, SaúdeManguinhos, Rio de Janeiro, v.21, n.4, p.1131-1149, 2014. https://doi.org/10.1590/S0104$\underline{59702014000400004}$

POPINIGIS, Fabiane. Proletários de casaca. Campinas: Editora da Unicamp, 2007.

PORTER, Roy. Os ingleses e o lazer. In: CORBIN, Alain (org.). História dos tempos livres. Lisboa: Teorema, 2001. p. 19-58. 
SCHETINO, André Maia. Pedalando na modernidade: a bicicleta e o ciclismo: uma análise comparada entre Rio de Janeiro e Paris na transição dos séculos XIX e XX. Rio de Janeiro: Apicuri, 2009.

SCHWARCZ, Lilia Moritz. As barbas do Imperador. São Paulo: Companhia das Letras, 1998.

SILVA, Carlos Leonardo Bahiense; MELO, Victor Andrade de. Fabricando o soldado, forjando o cidadão: o Dr. Eduardo Augusto Pereira de Abreu, a Guerra do Paraguai e a educação física no Brasil. História, Ciências, Saúde-Manguinhos, Rio de Janeiro, v.18, n.2, p.337-354, 2011. https://doi.org/10.1590/S0104-59702011000200005

SOARES, Carmen Lúcia. Corpo, Conhecimento e Educação: notas esparsas. In: SOARES, Carmen Lúcia (org.). Corpo e História. Campinas: Autores Associados, 2001. p. 109-129.

SOUZA, Gilda Mello e. O espírito das roupas: a moda no século XIX. São Paulo: Companhia das Letras, 1987.

THE RIO News, Rio de Janeiro 26 ago. 1889 b.

THE RIO News, Rio de Janeiro, 14 jan. 1889a. 